\title{
Inflammatory responses predict long-term mortality risk in community-acquired
} pneumonia

\author{
C. Guertler*, ${ }^{*}$, B. Wirz ${ }^{*, \$}$, M. Christ-Crain*, W. Zimmerli\#, B. Mueller ${ }^{\star}$ and P. Schuetz ${ }^{+}$
}

ABSTRACT: Long-term outcomes in patients surviving community-acquired pneumonia (CAP) are still incompletely understood. This study investigates the association of clinical parameters and blood markers with long-term mortality.

We prospectively followed 877 CAP patients from a previous multicentre trial for 18 months follow-up and investigated all-cause mortality following hospital discharge.

Overall mortality was $17.3 \%(95 \% \mathrm{Cl} 14.8-19.8 \%)$ with a $12.8 \%$ (95\% Cl $10.9-15.0 \%)$ mortality incidence rate per year. Initial risk assignment using the Pneumonia Severity Index was accurate during the 18 month follow-up. Multivariable regression models (hazard ratio, 95\% $\mathrm{Cl}$ ) designated the following as independent risk factors for long-term mortality: male sex (1.7, 1.2-2.5); chronic obstructive pulmonary disease $(1.5,1.1-2.1)$; neoplastic disease (2.5, 1.7-3.7); and highest quartile of peak pro-adrenomedullin level (3.3, 1.7-6.2). Initial presentation with temperature $>38.7 \mathrm{C}(0.4,0.2-0.6)$, chills $(0.6,0.4-0.99)$ and highest quartile of the inflammatory marker C-reactive-protein $(0.3,0.2-0.5)$ were independent protective factors. A weighted risk score based on these variables showed good discrimination (area under receiver operating characteristic curve $0.78,95 \% \mathrm{Cl}$ 0.74-0.82).

Pronounced clinical and laboratory signs of systemic inflammatory host response upon initial hospital stay were associated with favourable long-term prognosis. Further studies should address whether closer monitoring of high-risk CAP patients after hospital discharge favourably impacts long-term mortality.

KEYWORDS: Long-term follow-up, mortality, pneumonia, respiratory tract infection

ommunity-acquired pneumonia (CAP) has a substantial short-term mortality rate and accounts for almost $10 \%$ of the worldwide burden of morbidity and mortality [1-3]. Effort has been made to better understand short-term (30 day) mortality in CAP patients to guide site-of-care decisions and identify patients at risk who may benefit from distinct sepsis therapies [4]. The pneumonia severity index (PSI) is a valid risk assessment tool and categorises patients into five classes ranging from very low mortality $(<1 \%)$ to high mortality $(>20 \%)$ [5]. The data from recent studies suggest that some blood markers, e.g. pro-adrenomedullin (proADM) [6-11] or procalcitonin (PCT) [12-15], mirror the severity of infection and enhance clinical risk scores for short-term prognostication. However, less extensive research has been conducted for a better understanding of factors influencing longterm mortality after initial hospitalisation of CAP patients. Previous data suggest that patients who survive an initial CAP episode are at increased risk of mortality and recurrent infections in the months following hospital discharge [16-22], especially in patients $>40$ yrs of age [23]. CAP may be a consequence of a patient's poor general condition and severe underlying comorbidities, which place patients at risk of further infections and mortality [18]. In line with that, a smaller study suggested that comorbidities are more important mortality predictors compared with the age of patients per se [18]. The author recommended that older age should not be a sole criterion for withholding aggressive treatment of CAP and that a better understanding of prognostic factors for long-term mortality is needed.

\section{AFFILIATIONS}

*Dept of Internal Medicine, University Hospital Basel, Basel, "Dept of Internal Medicine, Kantonsspital Liestal, Liestal, and "Medical University Clinic, Kantonsspital Aarau, Aarau, Switzerland.

+Harvard school of Public Health, Boston, MA, USA

${ }^{\S}$ These authors contributed equally.

CORRESPONDENCE

B. Mueller

Medical University Clinic

Kantonsspital Aarau AG

Tellstrasse CH-5001 Aarau Switzerland

E-mail: Happy.mueller@unibas.ch

Received:

July 292010

Accepted after revision:

Oct 012010

First published online:

Nov 112010 
While short-term risk assessment may influence site-of-care decisions, better understanding of factors and predictors for long-term medical outcomes may improve discharge strategies and the follow-up management of patients in the outpatient setting. A more targeted and closer surveillance of high-risk patients after hospital discharge has the potential to lower both re-hospitalisation and mortality. In a study from Canada, longterm mortality of hospitalised patients with CAP correlated strongly with the initial PSI score suggesting that initial PSI score could also be used for long-term prognostication [16]. However, validation of these findings in an independent European setting is warranted. In addition, the performance of blood markers, which correlate with short-term risks for prediction of long-term mortality, has not been studied systematically. The aim of this study, therefore, was to investigate the long-term prognostic performance of the PSI score and the association of clinical parameters and different blood biomarkers with long-term mortality rate in a large cohort of patients with CAP from a previous multicentre study [24, 25].

\section{METHODS}

\section{Study sample and trial flow}

This is a prospective 18-month follow-up study including all CAP patients who were previously enrolled in a multicentre trial (ProHOSP trial) and who were discharged post-survival of an initial CAP episode [24, 25]. Patients were included from October 2006 to March 2008 in one of six participating centres in Switzerland. Inclusion criteria for patients were: written informed consent; age $\geqslant 18 \mathrm{yrs}$; and admittance from the community or a nursing home with the primary diagnosis of acute lower respiratory tract infection (i.e. $<28$ days). Patients were ineligible for the trial if they were not able to give written informed consent because of language restriction or severe dementia. Also excluded were patients with active intravenous drug use, severe immune-suppression other than corticosteroid use, poor medical condition with expected imminent death, patients with hospital-acquired pneumonia and patients with chronic infection necessitating antibiotic treatment. For the purpose of this study, acute lower respiratory tract infection was defined by at least one respiratory symptom (cough, sputum production, dyspnoea, tachypnoea and pleuritic pain) plus one auscultatory finding or sign of infection (core body temperature $>38^{\circ} \mathrm{C}$, shivers and white blood cell count $>10 \times 10^{9}$ or $<4 \times 10^{9}$ cells $\cdot \mathrm{L}^{-1}$ ) [4]. In addition, a new or increased infiltrate on a chest radiograph was mandatory for the diagnosis of CAP.

Patients were assessed clinically upon admission to the emergency department (ED) and followed during their course of hospitalisation until discharge. Blood was sampled on admission and at days 3,5 and 7 as well as on the day of discharge. The PSI was calculated for all patients upon admission to the ED, as described previously [5].

The study protocol was approved by the local ethical committees of Basel, Aarau, Luzern and Muensterlingen in Switzerland and all participants signed patient informed consent forms.

\section{Analysis population, end-points and covariates}

The primary analysis population contained 877 patients with the final diagnosis of CAP who survived their initial hospital stay. The primary end-point of this analysis was mortality following hospital discharge for CAP after a follow-up period of 18 months. For outcome assessment, telephone interviews were performed by blinded medical students using a systematic questionnaire on days 30, 180 and 540 (18 months). If the patient could not be reached, relatives or treating primary care physicians were contacted.

Pre-defined covariates for the Cox regression models were: well known mortality risk factors (i.e. age and sex); clinical signs of infection (body temperature and chills); and prognostic blood markers (proADM) or blood markers of infection and inflammation (white blood cells, C-reactive protein (CRP) and PCT). All continuous variables were transformed into quartiles before entering the regression models. The overall extent of inflammation was analysed against peak levels of blood markers and body temperature during hospitalisation instead of against the initial values upon presentation to the ED or the levels before hospital discharge, which may depend more on the lag time between start of infection and hospital admission, and length of stay, respectively.

Since the interventional arm in the ProHOSP trial was noninferior to the control group with respect to the risk of adverse outcomes and mortality after 30 days [25] and because there was no significant difference between the two randomisation arms regarding all-cause mortality after 18 months of follow-up (HR 1.04, 95\% CI 0.75-1.44; p=0.82), treatment assignment was not considered any further for this analysis.

\section{Statistical analyses}

Discrete variables are expressed as counts (percentage) and continuous variables as medians (interquartile ranges). If applicable, 95\% confidence intervals are provided. Frequency comparison was performed by Chi-squared test. Two-group comparison was done with non-parametric Mann-Whitney Utests. To assess the association of different predictors with outcomes, univariable and multivariable Cox regression analyses were calculated and hazard ratios (HRs) with 95\% confidence intervals are reported. Continuous predictors (age, temperature and biomarker levels) were transformed into quartiles before entering the models. For the time-to-event analysis patients were censored at the time of death, at the time of last contact for patients lost to follow-up or at study end (i.e. after 18 months). The proportional hazards assumption of Cox regression was evaluated by graphical display and analysis of the scaled Schoenfeld residuals as recommended [26]. For all variables, the simultaneous and individual variable significance tests based on the scaled Schoenfeld residuals were negative for proportionality assumption violations in the model. The association of different predictors and mortality were also displayed graphically in stratified Kaplan-Meier survival curves and log rank tests were used to compare groups. A weighted risk factor score was further calculated based on all independent predictors in the multivariable regression model assigning one, two or three points for each independent predictor depending on the strength of association. This score was compared to the PSI score in terms of discrimination in a receiver operating characteristics (ROC) analysis, where the area under the ROC (AUC) is a measure of overall discrimination. 
All statistical analyses were performed with STATA 9.2 (Stata Corp., College Station, TX, USA). All testing was two-tailed and p-values $<0.05$ were considered to indicate statistical significance.

\section{RESULTS}

\section{Baseline characteristics}

The initial cohort included a total of 1,304 patients including $925(71 \%)$ patients with a definite diagnosis of CAP. After exclusion of non-CAP patients and 48 CAP patients who did not survive the initial hospital stay, the primary analysis population included 877 CAP patients. The median age of the cohort was 73 yrs and 58\% were male. Patients had a high burden of comorbidities: 30\% underlying chronic obstructive pulmonary disease (COPD); 21\% chronic renal failure; 19\% coronary heart disease; and 18\% diabetes. Additional characteristics, including clinical history, clinical findings on admission to the ED, results from blood analysis and initial severity assessment with the PSI, are presented in table 1.

\section{Overall mortality during follow-up and in different PSI classes}

A total of $97.1 \%$ of patients or their families could be reached by phone after the 18 months of follow-up. In $12(1.3 \%)$ patients the survival status was confirmed with their primary care physician and $15(1.6 \%)$ patients were lost to follow-up. From the initial cohort of 877 CAP patients, 152 patients did not survive the 18 months follow-up, the overall mortality was therefore $17.3 \%(95 \% \mathrm{CI} 14.8-19.8 \%)$ corresponding to a mortality incidence rate of $12.8 \%$ (95\% CI $10.9-15.0 \%)$ per year.

When stratifying patients according to the initial PSI score at hospital admission, we found that patients in higher PSI classes had a significantly increased risk for subsequent mortality after hospital discharge compared with patients in lower PSI classes (fig. 1). The mortality rate per year increased from $2.7 \%$ in PSI classes $1 / 2$ to $19.4 \%$ and $34.1 \%$ in PSI class 4 and 5, respectively. Similarly, the HR of PSI class 4 and 5 was at 6.6 (95\% CI 3.4-12.8) and 11.6 (95\% CI 5.8-23.3), respectively, compared with PSI $1 / 2$ patients.

\section{Univariable association of baseline predictors and mortality in CAP patients}

The association of baseline characteristics, clinical parameters and blood biomarkers with 18 month mortality following hospital discharge was assessed in Cox regression models. HR from univariable analysis and mortality incidence rates per year are shown in table 2. Male sex, older age and different comorbidities carried a higher risk for mortality. Similarly, high peak levels of ProADM during initial hospitalisation were associated with higher risk of long-term mortality (fig. 2). The mortality rate per year increased from 6.5 in the lowest ProADM quartile to 25.9 in the highest quartile. Conversely, a history of chills, high initial body temperature and high peak CRP levels during initial hospitalisation was associated with lower risk for long-term mortality (fig. 3).

\section{Multivariable analysis}

The independent association of predictors and 18 month mortality in multivariable analysis (table 3) focusing on the

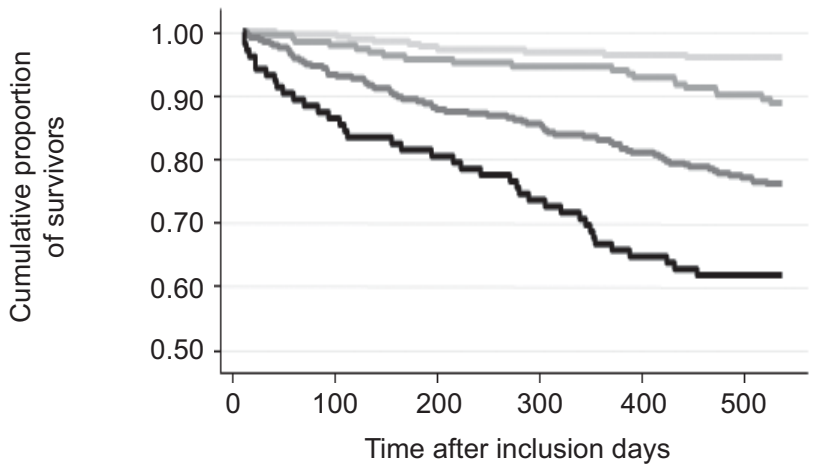

Number at risk

PSI class $1 / 2$

PSI class 3

PSI class $4-327$

322

PSI class $5 \quad 105$

$\begin{array}{ccc}261 & 247 & 246 \\ 183 & 175 & 173 \\ 300 & 283 & 276 \\ 90 & 84 & 77\end{array}$

$\begin{array}{ccl}245 & 244 & \\ 170 & 165 & \\ 262 & 250 & \\ 68 & 65 & \end{array}$

FIGURE 1. Kaplan-Meier survival analysis stratified by Pneumonia Severity Index (PSI) class ( $\mathrm{n}=877$ ). $\mathrm{p}<0.0001$ (log rank). 
TABLE 2 Univariable Cox regression model ${ }^{\#}$

Parameter

HR $(95 \% \mathrm{Cl})$

p-value

Mortality incidence rate per yr \%

(95\% Cl)

\section{Demographics}

Females

Males

1

$1.7(1.2-2.4)$

$0.4(0.3-0.6)$

History of chills

Temperature in the ED in quartiles

$<37.0^{\circ} \mathrm{C}$

$37.0-37.9^{\circ} \mathrm{C}$

$37.9-38.7^{\circ} \mathrm{C}$

$>38.7^{\circ} \mathrm{C}$

Age in quartiles

$<59$ yrs

59-73 yrs

73-82 yrs

$>82$ yrs

\section{Comorbidities}

Chronic heart failure

COPD

Diabetes mellitus

Neoplastic disease

Chronic renal failure

Initial severity assessment with PSI

Class $1 / 2$

Class 3

Class 4

Class 5

\section{Blood markers in quartiles}

CRP

$<105 \mathrm{mg} \cdot \mathrm{dL}^{-19,+}$

$105-181 \mathrm{mg} \cdot \mathrm{dL}^{-1}$

$181-265 \mathrm{mg} \cdot \mathrm{dL}^{-1}$

$>265 \mathrm{mg} \cdot \mathrm{dL}^{-1}$

Procalcitonin

$<0.21-0.70 \mathrm{ng} \cdot \mathrm{L}^{-1 \oplus,+}$

$0.21-0.70 \mathrm{ng} \cdot \mathrm{L}^{-1}$

$0.70-3.8 \mathrm{ng} \cdot \mathrm{L}^{-1}$

$>3.8 \mathrm{ng} \cdot \mathrm{L}^{-1}$

ProADM

$<0.83 \mathrm{nmol} \cdot \mathrm{L}^{-19},+$

$0.83-1.22 \mathrm{nmol} \cdot \mathrm{L}^{-1}$

$1.22-1.97 \mathrm{nmol} \cdot \mathrm{L}^{-1}$

$>1.97 \mathrm{nmol} \cdot \mathrm{L}^{-1}$

WBC

$<9.8$ cells $\times 10^{9} \cdot \mathrm{L}^{-19,+}$

9.8-13.0 cells $\times 10^{9} \cdot \mathrm{L}^{-1}$

13.0-17.4 cells $\times 10^{9} \cdot \mathrm{L}^{-1}$

$>17.4$ cells $\times 10^{9} \cdot \mathrm{L}^{-1}$

Albumin

$>39 \mathrm{~g} \cdot \mathrm{L}^{-1}$

$35-39 \mathrm{~g} \cdot \mathrm{L}^{-1}$

$30-35 \mathrm{~g} \cdot \mathrm{L}^{-1}$

$<30 \mathrm{~g} \cdot \mathrm{L}^{-1}$
1

$0.8(0.5-1.2)$

$0.9(0.6-1.3)$

$0.3(0.2-0.5)$

1

$1.6(1-2.5)$

$1.2(0.8-2)$

$0.8(0.5-1.3)$

1

$1.1(0.6-2)$

$2.4(1.4-4.1)$

$3.5(2.1-5.7)$

1

$1.3(0.8-2)$

$1.0(0.6-1.6)$

$1.2(0.8-1.9)$

1

$1.5(0.8-2.8)$

$1.5(0.9-2.8)$

$1.5(0.8-2.8)$
0.002

$<0.001$

0.898

0.378

0.005

0.01

$<0.001$

$<0.001$

0.012

0.01

0.148

$<0.001$

$<0.001$

0.003

$<0.001$

$<0.001$

0.219

0.526

$<0.001$

0.039

0.362

0.329

0.7

0.001

$<0.001$

0.29

0.915

0.418

0.179

0.143

0.176
$13.2(10.9-16.1)$

18.5 (16-21.4)

6.5 (4.4-9.6)

$15.9(11.8-21.4)$

15.3 (11.4-20.4)

$12.3(8.9-17)$

$8.9(6-13.2)$

$3.8(2.2-6.6)$

$9.8(6.8-14)$

$15.3(11.2-20.8)$

27.3 (21.5-34.5)

$21.4(15.6-29.4)$

$17.9(13.9-23.1)$

16.4 (11.6-23.2)

33.1 (24.3-45.1)

24.3 (18.5-31.8)

$2.7(1.4-5)$

$8.5(5.6-12.9)$

$19.4(15.5-24.1)$

34.1 (25-46.5)

18.1 (13.8-23.8)

$14.1(10.4-19)$

$15.3(11.3-20.6)$

$5.3(3.3-8.7)$

$11.0(7.9-15.4)$

$17.4(13.1-23)$

$13.4(9.7-18.4)$

$10.9(7.6-15.4)$

$6.5(4.3-10)$

$7.8(5.2-11.6)$

$16.6(12.4-22.1)$

25.9 (20-33.4)

$11.5(8.3-16)$

15.1 (11.3-20.3)

$11.1(7.8-15.7)$

14.6 (10.8-19.9)

$10.2(6.4-16.5)$

14.3 (9.8-20.9)

$15.4(11-21.4)$

14.3 (9.8-20.8)

HR: hazard ratio; ED: emergency department; COPD: chronic obstructive pulmonary disease; PSI: Pneumonia Severity Index; CRP: C-reactive protein; proADM: proadrenomedullin; WBC: white blood cells. ${ }^{\#}: \mathrm{n}=877 ;{ }^{\bullet}:$ reference group; ${ }^{+}$: peak levels during hospitalisation were used. 


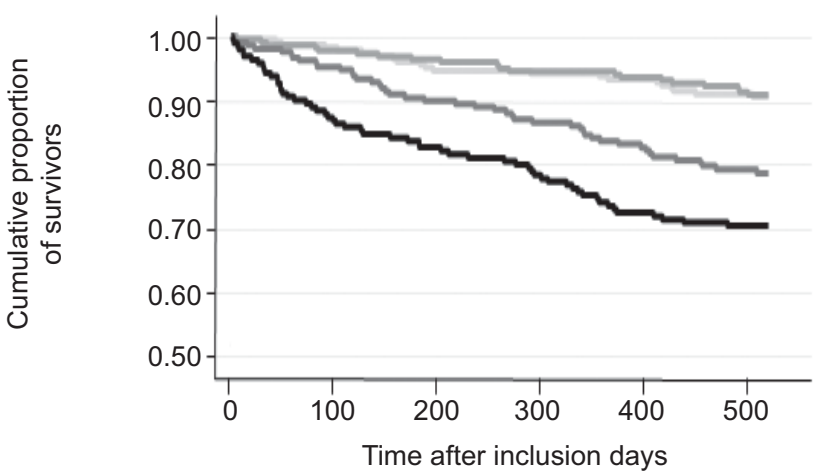

Number at risk

$\begin{array}{llllllll}\text { ProADM Q1 } & 231 & 227 & 213 & 212 & 209 & 204 & \\ \text { ProADM Q2 } & 220 & 215 & 209 & 205 & 203 & 200 & \\ \text { ProADM Q3 } & 214 & 204 & 190 & 184 & 176 & 167 & \\ \text { ProADM Q4 } & 193 & 169 & 158 & 153 & 139 & 136 & \end{array}$

FIGURE 2. Survival according to pro-adrenomedullin (ProADM) quartiles $(Q)$ $(n=877) . p<0.0001$ (log rank).

main predictors from the univariable model was further assessed. Male sex, pre-existing COPD, neoplastic disease and highest quartile of peak proADM levels $\left(>1.97 \mathrm{nmol} \cdot \mathrm{L}^{-1}\right)$ were independently associated with mortality. Conversely, history of chills, highest temperature quartile $\left(>38.7^{\circ} \mathrm{C}\right)$ and highest quartile of peak CRP levels $\left(>265 \mathrm{mg} \cdot \mathrm{dL}^{-1}\right)$ were associated independently with a lower mortality risk.

Based on the result of the multivariable regression model, a weighted clinical risk score was calculated assigning one, two or three points to each independent risk factor based on the strength of association in the regression model (table 3). Of note, points were also assigned for the absence of risk factors (chills) and lower temperature quartiles and CRP quartiles. This risk score showed a significant increase in mortality with increasing number of risk factors (ANOVA $\mathrm{p}<0.001$ ). The score significantly separated survivors from nonsurvivors in Kaplan-Meier curves (log rank p<0.001) (fig. 4).

Finally, to compare discrimination of these risk factors with the PSI score, we calculated a ROC analysis. With an AUC of 0.78 (95\% CI 0.74-0.82), the risk factor score indicated significantly better discrimination compared with the PSI (AUC 0.72, 95\% CI 0.69-0.76; $\mathrm{p}<0.01)$.

\section{DISCUSSION}

877 CAP patients who were discharged from hospital having survived an initial CAP episode were followed-up for a total of 18 months. The initial risk assessment with the PSI was accurate to predict long-term mortality. This was also true for clinical parameters and high proADM levels. Interestingly, it was revealed that a more pronounced pro-inflammatory response mirrored by a history of chills, high body temperature and high peak levels of the inflammatory blood marker CRP were independently associated with better long-term prognosis.

Previous studies have investigated long-term sequelae of CAP [16, 19-22]. JOHNSTONE et al. [16] recently investigated longterm morbidity and mortality of patients with CAP requiring hospitalisation using multiple linked administrative databases

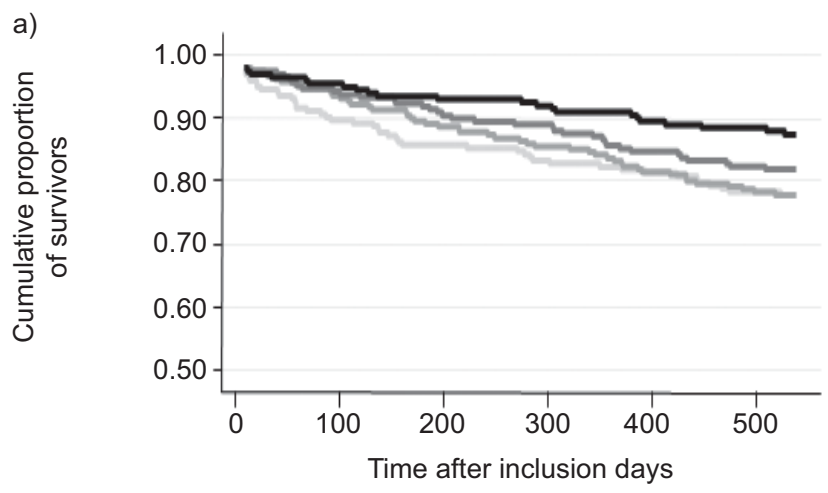

$\begin{array}{llllllll}\text { Number at risk } & & & & & & \\ \text { Temp Q1 } & 211 & 194 & 183 & 178 & 174 & 168 & \\ \text { Temp Q2 } & 232 & 221 & 206 & 199 & 190 & 183 & \\ \text { Temp Q3 } & 219 & 210 & 199 & 196 & 187 & 182 & \\ \text { Temp Q4 } & 203 & 197 & 190 & 188 & 183 & 181\end{array}$

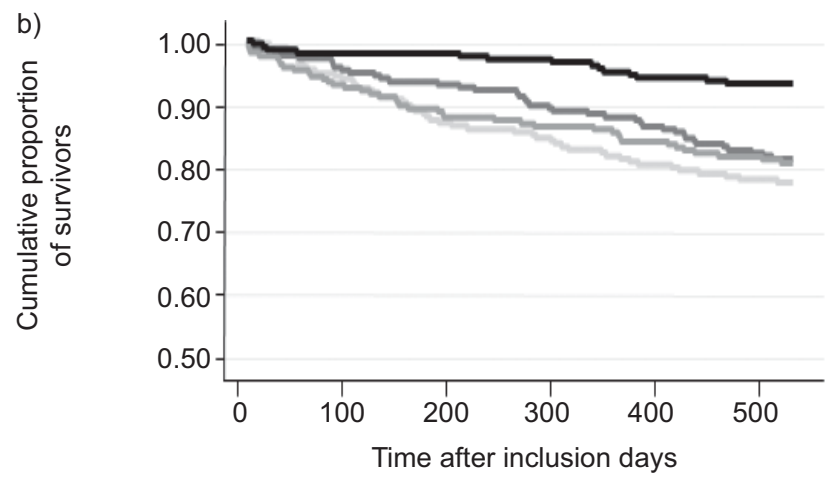

$\begin{array}{llllllll}\text { Number at risk } & & & & & & & \\ \text { CRP Q1 } & 221 & 208 & 189 & 184 & 175 & 170 & \\ \text { CRP Q2 } & 224 & 214 & 205 & 198 & 191 & 183 & \\ \text { CRP Q3 } & 218 & 202 & 189 & 186 & 181 & 175 & \\ \text { CRP Q4 } & 213 & 209 & 205 & 203 & 197 & 195 & \end{array}$

FIGURE 3. Survival according to a) temperature (temp) and b) C-reactive protein (CRP) quartiles $(\mathrm{Q})(\mathrm{n}=877$ ). a) $\mathrm{p}=0.017$ (log rank), b) $\mathrm{p}<0.0001$ (log rank).

in Canada after a median follow-up of 3.8 yrs. The 30-day and 1 -yr mortality rates $(12 \%$ and $28 \%$, respectively) were higher compared with our mortality rates, even when taking into account that the $5.6 \%$ nonsurvivors of the initial CAP episode were not included in our analysis, which may partly be explained by the higher percentage of high-risk patients $(63 \%$ PSI class 4 and 5) compared with our study. They found that advanced age, male sex and high initial PSI correlated with adverse prognosis. Similarly, MORTENSEN et al. [19] reported a 1 -yr mortality rate of $29 \%$ for CAP patients and that the initial PSI was accurate for risk assessment in CAP patients with a follow-up even after a follow-up of almost 6 yrs. The present study validates these data in a controlled prospective study and expands the findings to a European CAP population. Similarly, we found a reasonable performance of the PSI even after 18 months follow-up. The PSI is largely age driven and incorporates important comorbidities, which may explain its long-term prognostic performance. In line with that, EL SolH et al. [27] showed in a 1-yr follow-up of 301 consecutive patients hospitalised for CAP that Charlson 


\begin{tabular}{|c|c|c|c|}
\hline TABLE 3 Multiva & $x$ regression & nodel $^{\#}$ & \\
\hline Parameter & HR $(95 \% \mathrm{Cl})$ & $\mathrm{p}$-value & Risk points \\
\hline Males & $1.7(1.2-2.5)$ & 0.003 & 1 \\
\hline No chills & 1 & & 1 \\
\hline Chills & $0.6(0.4-1)$ & 0.049 & 0 \\
\hline \multicolumn{4}{|c|}{ Initial temperature in quartiles } \\
\hline$<37.0^{\circ} \mathrm{C}$ & 1 & & 1 \\
\hline $37.0-37.9^{\circ} \mathrm{C}$ & $0.8(0.5-1.3)$ & 0.391 & 1 \\
\hline $37.9-38.7^{\circ} \mathrm{C}$ & $0.9(0.6-1.5)$ & 0.749 & 1 \\
\hline$>38.7^{\circ} \mathrm{C}$ & $0.4(0.2-0.6)$ & $<0.001$ & 0 \\
\hline \multicolumn{4}{|l|}{ Age in quartiles } \\
\hline$<59 \mathrm{yrs}^{\circ}$ & 1 & & 0 \\
\hline $59-73$ yrs & $1.5(0.7-3.1)$ & 0.255 & 1 \\
\hline $73-82$ yrs & $2(1-4)$ & 0.066 & 2 \\
\hline$>82 \mathrm{yrs}$ & $3(1.5-6.1)$ & 0.002 & 3 \\
\hline \multicolumn{4}{|l|}{ Comorbidities } \\
\hline Chronic heart failure & $0.8(0.6-1.2)$ & 0.369 & 0 \\
\hline COPD & $1.5(1.1-2.1)$ & 0.020 & 1 \\
\hline Neoplastic disease & $2.5(1.7-3.7)$ & $<0.001$ & 2 \\
\hline Chronic renal failure & $1(0.7-1.5)$ & 0.958 & 0 \\
\hline \multicolumn{4}{|l|}{ Initial blood markers } \\
\hline \multicolumn{4}{|l|}{ ProADM } \\
\hline$<0.83 \mathrm{nmol} \cdot \mathrm{L}^{-19,++}$ & 1 & & 0 \\
\hline $0.83-1.22 \mathrm{nmol} \cdot \mathrm{L}^{-1}$ & $0.9(0.5-1.7)$ & 0.821 & 0 \\
\hline $1.22-1.97 \mathrm{nmol} \cdot \mathrm{L}^{-1}$ & $1.9(1.1-3.5)$ & 0.032 & 2 \\
\hline$>1.97 \mathrm{nmol} \cdot \mathrm{L}^{-1}$ & $3.3(1.7-6.2)$ & $<0.001$ & 3 \\
\hline \multicolumn{4}{|l|}{ CRP } \\
\hline$<105 \mathrm{mg} \cdot \mathrm{dL}^{-1 \oplus,+}$ & 1 & & 3 \\
\hline $105-181 \mathrm{mg} \cdot \mathrm{dL}^{-1}$ & $0.8(0.5-1.2)$ & 0.288 & 2 \\
\hline $181-265 \mathrm{mg} \cdot \mathrm{dL}^{-1}$ & $0.7(0.5-1.2)$ & 0.187 & 1 \\
\hline$>265 \mathrm{mg} \cdot \mathrm{dL}^{-1}$ & $0.3(0.2-0.5)$ & $<0.001$ & 0 \\
\hline
\end{tabular}

COPD: chronic obstructive pulmonary disease; pro-ADM: pro-adrenomedullin; CRP: C-reactive protein. ${ }^{*}: \mathrm{n}=877$; ${ }^{\circ}$, reference group; ${ }^{+}$: peak levels during hospitalisation were used.

comorbidity index was highly predictive of 1-yr hospital readmission or death. Still, the PSI may not be optimal for assessing long-term prognosis because it includes severity criteria of the infection, such as body temperature, which may be associated with short-term mortality but not adverse longterm prognosis, as evidenced in the present study.

An interesting finding of this study is that the extent of inflammatory host response mirrored by a history of chills, high initial body temperature and high peak levels of CRP were protective for long-term survival. This was also true when adjusted for potential confounders such as age and comorbidities. This finding is somewhat counterintuitive as most studies have shown that a strong inflammatory response is associated with adverse short-term outcomes. Some studies found CRP to be a predictor for CAP-associated mortality [28-30], while other studies found no association in the short term [31]. Interestingly, one large follow-up study of patients with CAP enrolled in the Pneumonia Patient Outcomes Research Team cohort reported that the lack of feeling feverish was associated with higher long-term mortality among patients with pneumonia compared with age-matched controls [19]. Based on the

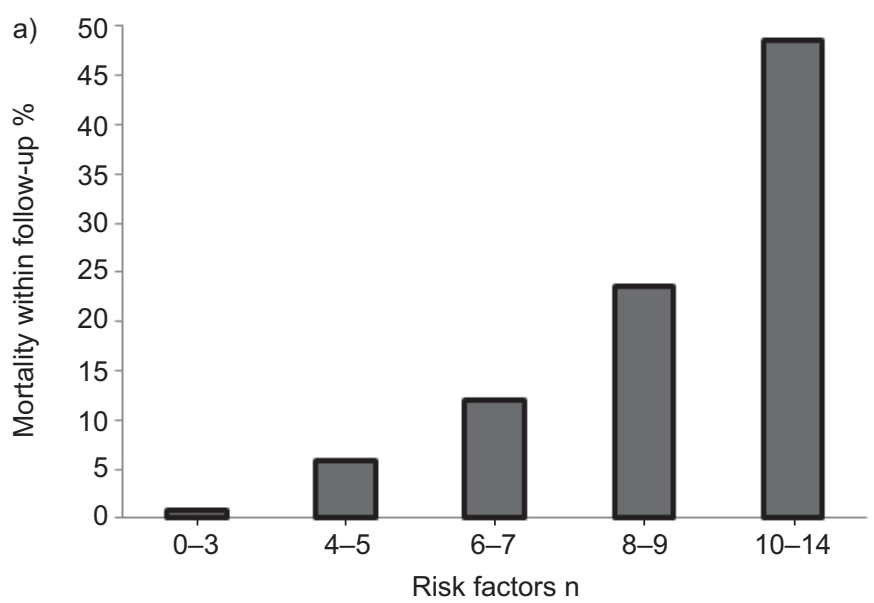

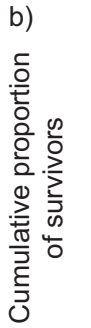

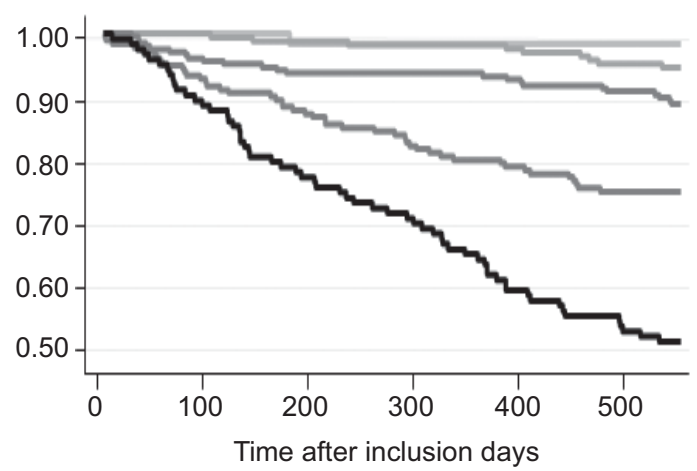

Number at risk

$\begin{array}{lllllll}\text { 0-3 points } & 113 & 113 & 106 & 106 & 106 & 106 \\ \text { 4-5 points } & 187 & 187 & 180 & 179 & 177 & 174 \\ \text { 6-7 points } & 218 & 209 & 203 & 203 & 199 & 197 \\ \text { 8-9 points } & 195 & 180 & 169 & 160 & 155 & 148 \\ \text { 10-14 points } & 132 & 118 & 104 & 95 & 82 & 74\end{array}$

FIGURE 4. Long-term survival according to number of risk factors. a) Mortality with increasing number of risk factors and b) survival according to number of risk factors. a) $p<0.01$ (ANOVA, b) $p<0.001$ (log rank).

results of these studies, it is tempting to hypothesise that survival of a clinically and biochemically pronounced CAP may mirror a more robust host defence and a better general condition with resulting lower complications at long-term in this population. Although we adjusted our analysis for age, some residual confounding factors may still be present because factors such as fever and chills are inversely correlated with age $[19,32]$. Further investigation is warranted to validate these findings and determine the mechanism for these effects.

Previous studies investigated the association of different blood biomarkers with distinct pathophysiological mechanisms, such as inflammatory response or abnormalities in the cardiovascular and renal system with long-term outcome in sepsis and respiratory tract infection. READE et al. [33] found that higher initial concentrations of interleukin (IL)-6 and IL-10 were associated with lower survival at day 180. In addition, higher D-dimers (marker of fibrinolysis) and lower antithrombin III (marker for coagulation) were also risk factors for a fatal outcome. High initial IL-6 levels were again associated with adverse outcome after a follow-up of 9 yrs in another study 
from Germany [34]. In addition, a study found that despite clinical recovery, many CAP patients leave the hospital with ongoing inflammation and that this residual inflammation is associated with an increased risk of death in the follow-up [17]. Specifically, the authors of this last study found higher IL-6 and IL-10 levels at hospital discharges to be associated with an increased risk of death. Within this study, we focused on peak levels of blood markers and body temperature during hospitalisation because these mirror the overall extent of inflammation and may depend less on length of stay. In line with these previous findings peak proADM levels in the present study were associated independently with long-term survival. ProADM is a potent vasodilating agent with immune modulating, metabolic and bactericidal properties $[35,36]$. It remains unclear whether the association of high proADM levels and lower long-term survival reflects a more severe initial infection which could impact negatively on the general condition of patients, or whether a worse general condition is associated with lower immune function leading to a more rapidly expanding respiratory infection (or both). Importantly, associations in statistical models do not prove causal relationships, but may still provide a rationale for future interventional studies. For example, an improved long-term risk assessment has influenced the management of different diseases, such as chronic heart failure and coronary heart disease. Cardiovascular guidelines recommend only treating patients at high risk with statins because the number needed-to-treat to prevent one cardiovascular complication is more favourable for patients at higher risk for adverse outcome instead of indiscriminately treating all patients [37]. In CAP patients it remains to be determined whether the identification of high-risk patients could influence long-term management since no specific preventative therapies are available today. However, a closer follow-up in patients at highest risk may translate into better outcomes. This should be assessed in future prospective trials.

Strengths of this study include the large sample size and the thorough initial clinical examination with collection of different blood markers and follow-up with only very few patients lost to follow-up. Telephone interviews were used to assess survival status and recurrence rates. Family and physicians were contacted to verify the information. Still, the following limitations need consideration: definitive causes of mortality were not further investigated; all-cause mortality rather than diseasespecific mortality was reported; and the study was conducted in different hospitals in Switzerland and results may not unconditionally be applied to other settings and regions. Finally, interventional studies are needed to investigate whether improved risk classification translates into better outcomes.

In conclusion, CAP carries an increased risk for mortality, even after successful initial treatment. Although only derived and validated for 30-day outcomes, the PSI and other clinical parameters and blood biomarker levels were accurate predictors for long-term outcomes, with an intact host response indicating favourable long-term outcome. Future studies should address whether better monitoring of high-risk patients after hospitalisation for CAP may help to reduce long-term mortality.

\section{STATEMENT OF INTEREST}

Statements of interest for M. Christ-Crain, B. Mueller and P. Schuetz can be found at www.erj.ersjournals.com/site/misc/statements.xhtml

\section{ACKNOWLEDGEMENTS}

We thank E. Tighe (Basel, Switzerland) for helpful scientific discussion. We are grateful to the Data Safety and Monitoring Board, namely A.P. Perruchoud (University Hospital Basel, Basel, Switzerland), S. Harbarth (University Hospital Geneva, Geneva, Switzerland) and A. Azzola (University Hospital Basel) for continuous supervision of this trial and all local physicians, the nursing staff and the patients and their relatives who participated in this study. Especially, we thank the staff of the emergency room, medical clinics and central laboratories of the University Hospital Basel (Basel, Switzerland), the Cantonal Hospitals Liestal, Aarau, Luzern and Muensterlingen and the "Buergerspital" Solothurn (all Switzerland) for their very helpful assistance, patience and technical support. We thank other members of the ProHOSP Study Group for their important help during the study.

The ProHOSP Study group included the following persons: U. Schild, K. Regez, R. Bossart, M. Wolbers, C. Blum, S. Neidert, I. Suter, H.C. Bucher, F. Mueller, A. Chaudry, J. Haeuptle, R. Zarbosky, R. Fiumefreddo, M. Wieland, C. Nusbaumer, A. Christ, R. Bingisser and K. Schneider (all University Hospital Basel, Basel, Switzerland); R. Thomann, R. Schoenenberger and R. Luginbuehl (all Buergerspital Solothurn, Solothurn, Switzerland); T. Fricker, C. Hoess, M. Krause, I. Lambinon and M. Zueger (all Kantonsspital Muensterlingen, Muensterlingen, Switzerland); C. Henzen and V. Briner (both Kantonsspital Luzern, Luzern, Switzerland); T. Bregenzer, D. Conen, A. Huber and J. Staehelin (all Kantonsspital Aarau, Aarau, Switzerland); and C. Falconnier and C. Bruehlhardt (both Kantonsspital Liestal, Liestal, Switzerland).

\section{REFERENCES}

1 Menendez R, Torres A, Zalacain R, et al. Risk factors of treatment failure in community acquired pneumonia: implications for disease outcome. Thorax 2004; 59: 960-965.

2 Almirall J, Bolibar I, Vidal J, et al. Epidemiology of communityacquired pneumonia in adults: a population-based study. Eur Respir J 2000; 15: 757-763.

3 Macfarlane J, Lewis SA, Macfarlane R, et al. Contemporary use of antibiotics in 1089 adults presenting with acute lower respiratory tract illness in general practice in the UK: implications for developing management guidelines. Respir Med 1997; 91: 427-434.

4 Niederman MS, Mandell LA, Anzueto A, et al. Guidelines for the management of adults with community-acquired pneumonia. Diagnosis, assessment of severity, antimicrobial therapy, and prevention. Am J Respir Crit Care Med 2001; 163: 1730-1754.

5 Fine MJ, Auble TE, Yealy DM, et al. A prediction rule to identify low-risk patients with community-acquired pneumonia. $N$ Engl Med 1997; 336: 243-250.

6 Struck J, Tao C, Morgenthaler NG, et al. Identification of an adrenomedullin precursor fragment in plasma of sepsis patients. Peptides 2004; 25: 1369-1372.

7 Christ-Crain M, Morgenthaler NG, Struck J, et al. Mid-regional pro-adrenomedullin as a prognostic marker in sepsis: an observational study. Crit Care 2005; 9: R816-R824.

8 Christ-Crain M, Morgenthaler NG, Stolz D, et al. Pro-adrenomedullin to predict severity and outcome in community-acquired pneumonia [ISRCTN04176397]. Crit Care 2006; 10: R96.

9 Schuetz P, Christ-Crain M, Morgenthaler NG, et al. Circulating precursor levels of endothelin-1 and adrenomedullin, two endothelium-derived, counteracting substances, in sepsis. Endothelium 2007; 14: 345-351.

10 Huang DT, Angus DC, Kellum JA, et al. Midregional proadrenomedullin as a prognostic tool in community-acquired pneumonia. Chest 2009; 136: 823-831.

11 Schuetz P, Wolbers M, Christ-Crain M, et al. Prohormones for prediction of adverse medical outcome in community-acquired 
pneumonia and lower respiratory tract infections. Crit Care 2010; 14: R106.

12 Huang DT, Weissfeld LA, Kellum JA, et al. Risk prediction with procalcitonin and clinical rules in community-acquired pneumonia. Ann Emerg Med 2008; 52: 48-58.

13 Jensen JU, Heslet L, Jensen TH, et al. Procalcitonin increase in early identification of critically ill patients at high risk of mortality. Crit Care Med 2006; 34: 2596-2602.

14 Haeuptle J, Zaborsky R, Fiumefreddo R, et al. Prognostic value of procalcitonin in Legionella pneumonia. Eur J Clin Microbiol Infect Dis 2009; 28: 55-60.

15 Schuetz P, Suter-Widmer I, Chaudri A, et al. Prognostic value of procalcitonin in community-aquired pneumonia. Eur Respir J 2011; 37: 384-392.

16 Johnstone J, Eurich DT, Majumdar SR, et al. Long-term morbidity and mortality after hospitalization with community-acquired pneumonia: a population-based cohort study. Medicine (Baltimore) 2008; 87: 329-334.

17 Yende S, Tuomanen EI, Wunderink R, et al. Preinfection systemic inflammatory markers and risk of hospitalization due to pneumonia. Am J Respir Crit Care Med 2005; 172: 1440-1446.

18 Brancati FL, Chow JW, Wagener MM, et al. Is pneumonia really the old man's friend? Two-year prognosis after community-acquired pneumonia. Lancet 1993; 342: 30-33.

19 Mortensen EM, Kapoor WN, Chang CC, et al. Assessment of mortality after long-term follow-up of patients with communityacquired pneumonia. Clin Infect Dis 2003; 37: 1617-1624.

20 Winters BD, Eberlein M, Leung J, et al. Long-term mortality and quality of life in sepsis: a systematic review. Crit Care Med 2010; 38: 1276-1283.

21 Koivula I, Sten M, Makela PH. Prognosis after communityacquired pneumonia in the elderly: a population-based 12-year follow-up study. Arch Intern Med 1999; 159: 1550-1555.

22 Hedlund JU, Ortqvist AB, Kalin ME, et al. Factors of importance for the long term prognosis after hospital treated pneumonia. Thorax 1993; 48: 785-789.

23 Waterer GW, Kessler LA, Wunderink RG. Medium-term survival after hospitalization with community-acquired pneumonia. Am J Respir Crit Care Med 2004; 169: 910-914.

24 Schuetz P, Christ-Crain M, Wolbers M, et al. Procalcitonin guided antibiotic therapy and hospitalization in patients with lower respiratory tract infections: a prospective, multicenter, randomized controlled trial. BMC Health Serv Res 2007; 7: 102.
25 Schuetz P, Christ-Crain M, Thomann R, et al. Effect of procalcitonin-based guidelines $v s$ standard guidelines on antibiotic use in lower respiratory tract infections: the ProHOSP randomized controlled trial. JAMA 2009; 302: 1059-1066.

26 Grambsch PM, Therneau TM, Fleming TR. Diagnostic plots to reveal functional form for covariates in multiplicative intensity models. Biometrics 1995; 51: 1469-1482.

27 El Solh A, Pineda L, Bouquin P, et al. Determinants of short and long term functional recovery after hospitalization for communityacquired pneumonia in the elderly: role of inflammatory markers. BMC Geriatr 2006; 6: 12.

28 Almirall J, Bolibar I, Toran $\mathrm{P}$, et al. Contribution of C-reactive protein to the diagnosis and assessment of severity of communityacquired pneumonia. Chest 2004; 125: 1335-1342.

29 Menendez R, Martinez R, Reyes S, et al. Stability in communityacquired pneumonia: one step forward with markers? Thorax 2009; 64: 987-992.

30 Seligman R, Meisner M, Lisboa TC, et al. Decreases in procalcitonin and C-reactive protein are strong predictors of survival in ventilator-associated pneumonia. Crit Care 2006; 10: R125.

31 Muller B, Harbarth S, Stolz D, et al. Diagnostic and prognostic accuracy of clinical and laboratory parameters in communityacquired pneumonia. BMC Infect Dis 2007; 7: 10 .

32 Metlay JP, Schulz R, Li YH, et al. Influence of age on symptoms at presentation in patients with community-acquired pneumonia. Arch Intern Med 1997; 157: 1453-1459.

33 Reade MC, Yende S, D'Angelo G, et al. Differences in immune response may explain lower survival among older men with pneumonia. Crit Care Med 2009; 37: 1655-1662.

34 Baune BT, Rothermundt M, Ladwig KH, et al. Systemic inflammation (interleukin 6) predicts all-cause mortality in men: results from a 9-year follow-up of the MEMO Study. Age (Dordr) 2010; [Epub ahead of print DOI: 10.1007/s11357-010-9165-5].

35 Morgenthaler NG, Struck J, Alonso C, et al. Measurement of midregional proadrenomedullin in plasma with an immunoluminometric assay. Clin Chem 2005; 51: 1823-1829.

36 Eto T. A review of the biological properties and clinical implications of adrenomedullin and proadrenomedullin N-terminal 20 peptide (PAMP), hypotensive and vasodilating peptides. Peptides 2001; 22: 1693-1711.

37 Tenenbaum A, Fisman EZ. "If it ain't broke, don't fix it": a commentary on the positive-negative results of the ACCORD Lipid study. Cardiovasc Diabetol 2010; 9: 24. 